\title{
Wind Driving Triboluminescence Technology: A Physical Agriculture Method of Pest Insects Control without Pesticides ${ }^{\dagger}$
}

\author{
ZHOU Qiang, ${ }^{1, *}$, Wang Jian-chao ${ }^{1}$ and Li Zhi-shen ${ }^{1}$ \\ ${ }^{1}$ Department of Mechatronics, College of Engineering, China Agricultural University, 100083 Tsinghua Dong Road, Beijing, China
}

\begin{abstract}
Some of triboluminescence materials have the property of shortwave light emission, which is possible to make them being used as the light resource of pest-insects phototaxis trapping. The inorganic composite phosphors $\mathrm{Sr}_{2} \mathrm{MgSi}_{2} \mathrm{O}_{7}$ :Ce and organic composite phosphor Mn-PMBB are tested to have the violet-blue spectrum and green spectrum glowing respectively; Their vertical axis wind driving triboluminescence unit is designed and fabricated on the basis of squirrel cage structure friction pair with multi-glass bars against on the cylindrical phosphor. The persistant wind driving tribo-luminescence is obtained in the experiment of wind driving triboluminescence unit. Further the triboplasma of $\mathrm{N}_{2}$ and $\mathrm{N}_{2}$ Ar gases closed in the quartz tube is researched by means of PTFE elctret on quartz tube friction pair, and a high intensity triboplasma light emission with more than 50000 counts is obtained in the span of $310-420 \mathrm{~nm}$ spectrum that supplies a more suitable shortwave spectrum of phototaxis trapping pest insects. The annular quartz glass tube is designed to constitute PTFE against on quartz friction pair; The triboplasma emission device is fabricated utilizing three stacking layer structure of PTFE-anuular quartz tube friction pairs, and the S-type vertical shaft wind tuebine is used to form the wind driving triboplasma emission unit. The violet-blue emission spectrum of $\mathrm{N}_{2}-\mathrm{Ar}$ gas troboplasma is obtained in the test of vertical wind driving triboplasma unit.
\end{abstract}

\section{Introduction}

In 21 th century, Chinese agricultural production is fast advancing from traditional chemical agriculture to organic agriculture. This presents in two aspects: the application of modern agricultural technology and the emphasis of ecological environment protection.

For traditional agriculture, the utility of agricultural pesticides kills effectively with poison the pest insects, but it leads to the agricultural non-point source pollution, which involves the pollution of soil, air and underground water, even serious residues in plant and products. Therefore, in order to adapt the requirement of organic agriculture development, a new agricultural production mode called physical agriculture presents in the modern agricultural production[1,2].

Among a series of physical agriculture technologies, the phototaxis trapping pests-killing lamp technology $[3,4]$ substitute for pesticide spraying pests-killing; and the space electric field sterilization technology[2,5] makes up for agricultural bactericides requiment. It really is a good guarantee that realize the agricultural pesticides "zero-growth" goal in Chinese Thirteenth Five-Year Plan.

Normally the phototaxis trapping pests-killing lamps distrubuted in the farm fields and vast grasslands need the electricity to light the lamps. This needs either electric supply, or solar energy cell in the crop field. At same time the pests-killing lamp rely mainly on the shortwave spectrum emission to trapping pest-insect[6].

This paper suggests the wind driving triboluminescence technologies to obtain the shortwave emission of pest-insect photaxis trapping. It relies only on the machinary friction function to stimulate the working matters to give out the light, in which the electricity generating and transfering system are omitted. This supply a easy measure of physical agriculture plant protection, at same time it is beneficial to uitilize windy enegy rescource especially in the vast grassland and mountain forest.

\section{Phosphor triboluminescence property and wind driving friction unit}

The material friction process lead to the elastic deformation, plastic deformation, and even crystalline fracture in the friction surface. This induces the electron transition, tribological electrification, frictional flash temperature, etc. The phenomenon of triboluminescence get a raise with this process for some of materials. The triboluminescence materials involve the inorganic composide phosphors and organic composide phosphor. They demonstrate the mechaluminescence property and photoluminescence property in our research.

The earth dopping silicate phosphor $\mathrm{Sr}_{2} \mathrm{MgSi}_{2} \mathrm{O}_{7}: \mathrm{Ce}$ is composited by high temperature calcining method, and

* Corresponding author: zq@cau.edu.cn 
its triboluminescence property is determined in the modified MCJ-01A sliding friction tester. Figure 1 presents the shortwave triboluminescent properties of $\mathrm{Sr}_{2} \mathrm{MgSi}_{2} \mathrm{O}_{7}$ :Ce phosphors prepared by $1200^{\circ} \mathrm{C}$ calcining temperatures in the sliding friction of $53 \mathrm{~N}$ applied load. It can be seen the prepared phosphors with 0.010 molar $\mathrm{Ce}$ doping concentration in the $\mathrm{Sr}_{2} \mathrm{MgSi}_{2} \mathrm{O}_{7}$ : Cex submits the property of shortwave emission with the peak wavelength $444 \mathrm{~nm} \pm$, full width at half maximum (FWHM) $110 \mathrm{~nm} \pm$ and emission intensity 305 counts \pm .

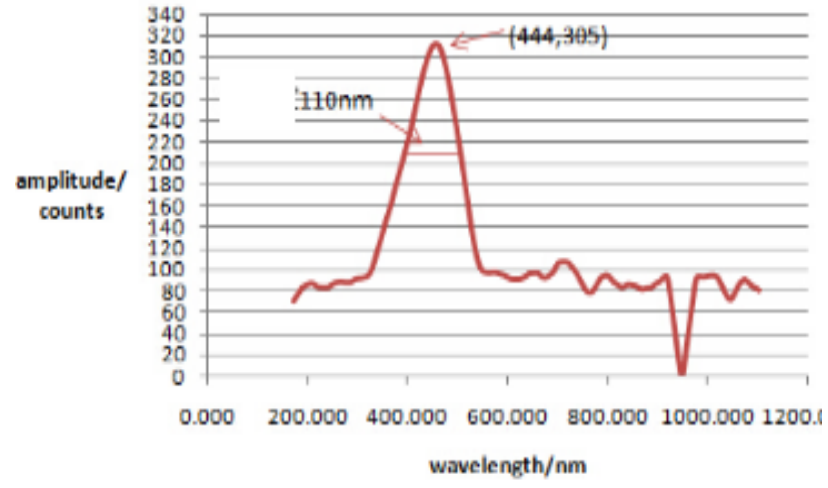

Fig. 1. TL spectrum of phosphor $\mathrm{Sr}_{2} \mathrm{MgSi}_{2} \mathrm{O}_{7}$ : $\mathrm{Cex}$, $\mathrm{x}=0.010 \mathrm{~mol}$

Figure 2 presents the triboluminescence property of prepared organic phosphor, Mn coordinative methyltriphenyl Phosphonium Bromide(PMBB) sample in the sliding friction with applied load $46.4 \mathrm{~N}$. It can seen that PMBB presents the green triboluminescence with $517 \mathrm{~nm}$ peak wavelength, 386 counts luminous intensity and 50 nm FWHM, and the luminous spectrum possess the single peak feature.

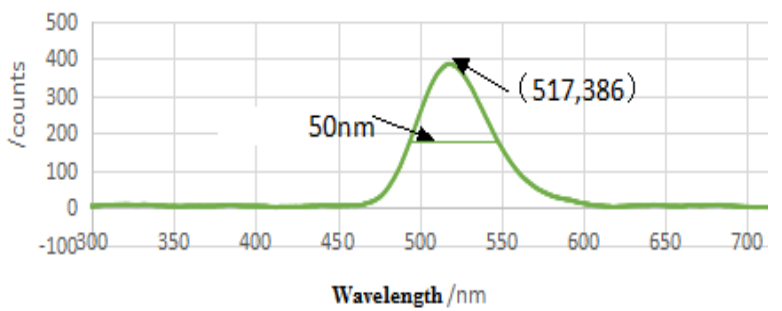

Fig. 2. TL property of PMBB phosphor

On the basis of triboluminescence phosphor property and its cylindrical forming sample, the squirrel cage structure is designed to construct the rubbing pairs of tribological luminous unit with multiple rubbing bars against on the cylindrical phosphor coating or block sample, as shown in figure 3.

The unit is mounted on the basis and was driven by vertical axis wind turbine connecting to the top of center axis of unit. The multiple rubbing bars against on the cylindrical phosphor can stimulate more tribological luminous flux, and the rotating TL unit also satisfy the $360^{\circ}$ azimuth light emitting. The vertical wind turbine can avoid the disturbance of rotating turbine blades on the outside forward light emitting of triboplasma in the horizontal direction. The entity image of this vertical axis wind driving triboluminescence unit is shown in figure 4.
Figure 5 presents the triboluminescence image of this vertical axis wind driving triboluminescence unit with organic Mn coorditive PMBB as phosphor material. Obviously the unit can generate a persistant glowing band that will supply the fluorescence requiement of shortwave phtotaxis trapping pest-insects.

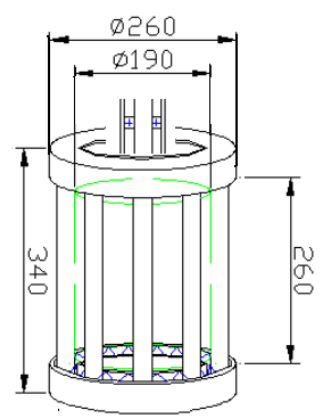

Fig. 3. Tribological luminescence pair of squirrel cage structure with multiple rubbing bars

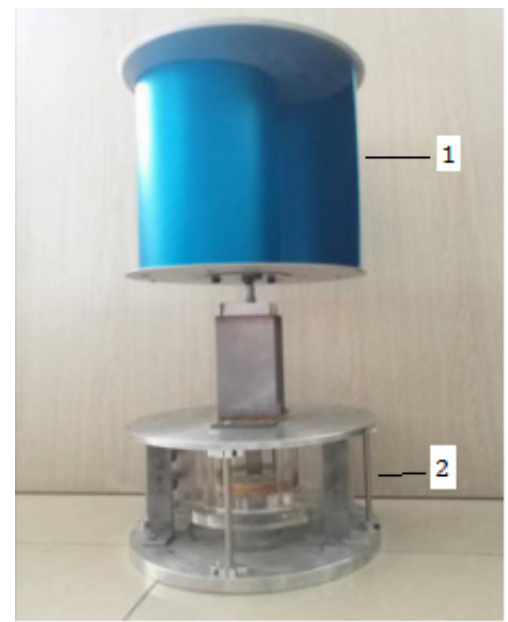

Fig. 4. Entity image of vertical axis wind driving triboluminescence unit

1. S-type wind turbine; 2. squirrel cage tribo-unit.

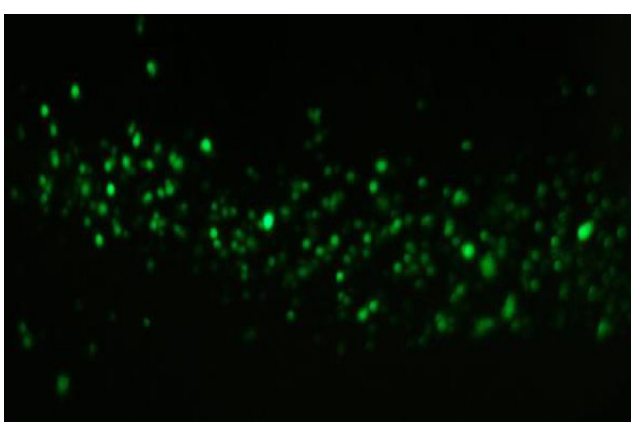

Fig. 5. Persistant glowing image of wind driving triboluminescence unit.

\section{$3 \mathrm{~N}_{2}$-Ar triboplasma glow and wind driving friction unit}

Another triboluminescence mechanism is the triboplasma light emition induced by the high voltage field of triboelectrifcation. Figure 6 indicates the principle of gas triboplasma emission generated in the closed quartz glass tube in the sliding friction of PTFE against on the 
tube. Owing to the electret character of PTFE material, its tribocharge lead to a high voltage field on the interface between PTFE and quartz tube. This must stimulate the exitation of electron enegy state of gases in the tube, therefore a high intensive plasma emission takes place.

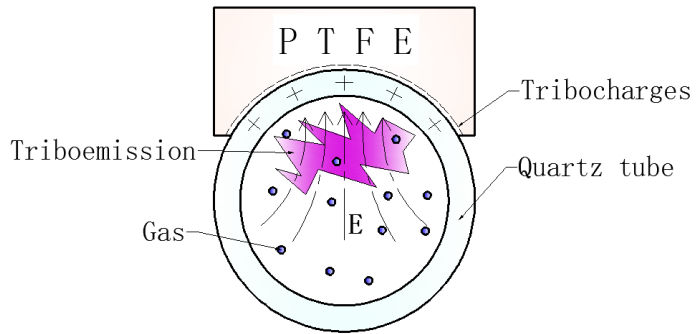

Fig. 6. Principle of gas triboplasma emission in closed quartz glass tube in frictional process

Figure 7 presents the triboplasma emission spectrum of $\mathrm{N}_{2}$ and $\mathrm{N}_{2}$-Ar in the negtive pressure. It can be seen that pure $\mathrm{N}_{2}$ can get the high intensive triboplasma emission with 36000 counts \pm and the $\mathrm{N}_{2}$-Ar mixture gas get a super intensity triboplasma emitting with more than 50000 counts. It shows the addition of inertia gas Ar is beneficial to improve the triboplasma emission of pure $\mathrm{N}_{2}$ gas.

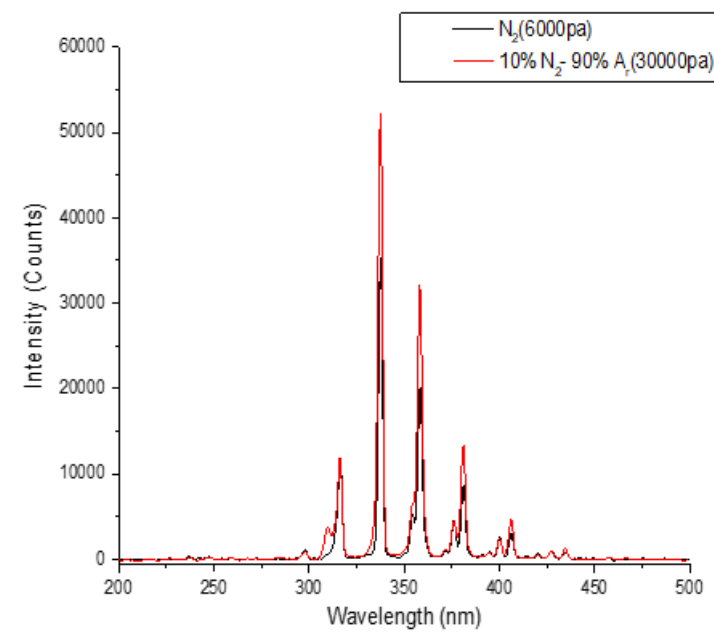

Fig. 7. Spectrum of $N_{2}$ and $N_{2}$-Ar triboplasma induced by mechanical friction

Figure 8 indicates the annular structure design of PTFE against on quartz tube. It transfer the straighter line sliding movement of PTFE on quartz tube surface to the anuular rotating movement of PTFE on quartz tube. This is specialy beneficial to realize the vertical shaft wind turbine drive of the frictional pair.

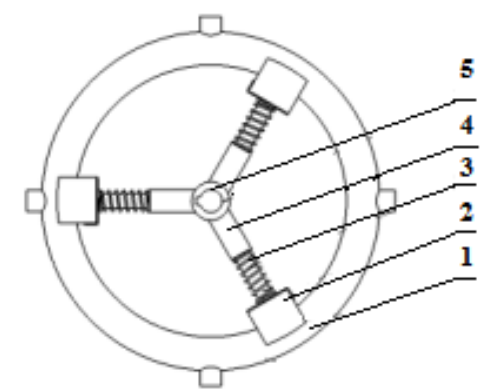

Fig. 8. Anuular structure design of PTFE on quartz tube friction pair

1. Annular Glass Tube; 2. PTFE part; 3. Loading Spring; 4. Rotating Part; 5. Center Shaft

Figure 9 presents the entity image of triboplasma emitting unit with three stacking layer structure of PTFE-anuular quartz tube friction pair. It can be seen that a total structure of triboplasma emitting unit is constituted according to vertical shaft wind turbine driving style and more intensive light emitting requirment. According to annular friction pair shown in figure 8 , the triboplasma emiting unit with three stacking layers of friction unit(2) is designed on the basis of vertical shaft S-type wind turbine(1). Impotantly the structure of three staching layers structure can supply a high intensity of triboplasma light emission than single PTFE-Annular Tube friction pair. So it will satisfy a basic threshold requirment for light scource emmitting intensity of trapping pest insects. And the vertical wind turbine avoids the disturbance of rotating turbine blades on the forward light emitting of triboplasma in glass tube (2) installed by horizontal direction.

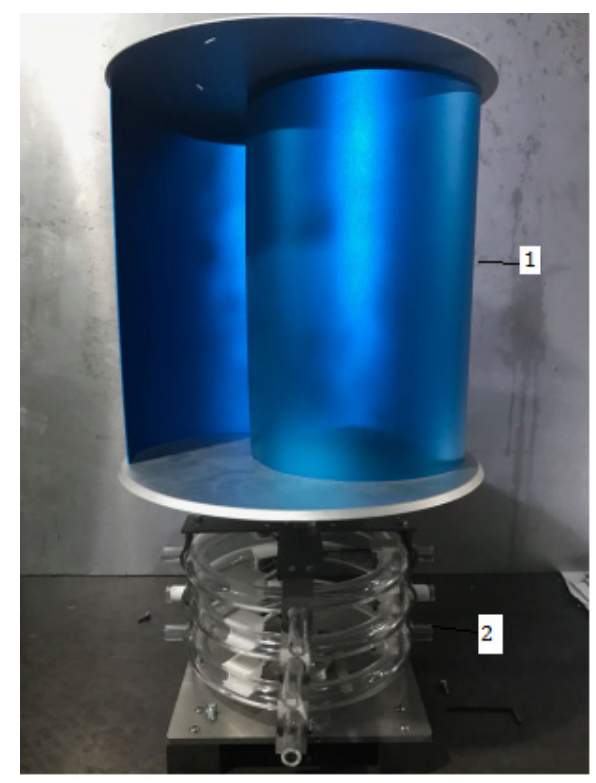

Fig. 9. Entity image of wind driving triboplasma unit with three stacking layer structure of PTFE-cyclar quartz tube friction pair

1. S-type wind turbine; 2. three layer tribopair unit.

Figure 10 indicates the image of triboplasma glowing in this wind driving triboplasma unit test. Utilizing $90 \% \mathrm{Ar}+10 \% \mathrm{~N}_{2}$ mixture gas with 30000pa negtive 
pressure in quartz tube, the blue-violet light emitting is obtained in the $0.2 \mathrm{~N}$ contact load and $0.50 \mathrm{~m} / \mathrm{s}$ sliding rate when the S-type wind turbine blade keeps a rotating velocity of $50 \mathrm{r} / \mathrm{m}$ drived by blast blower.

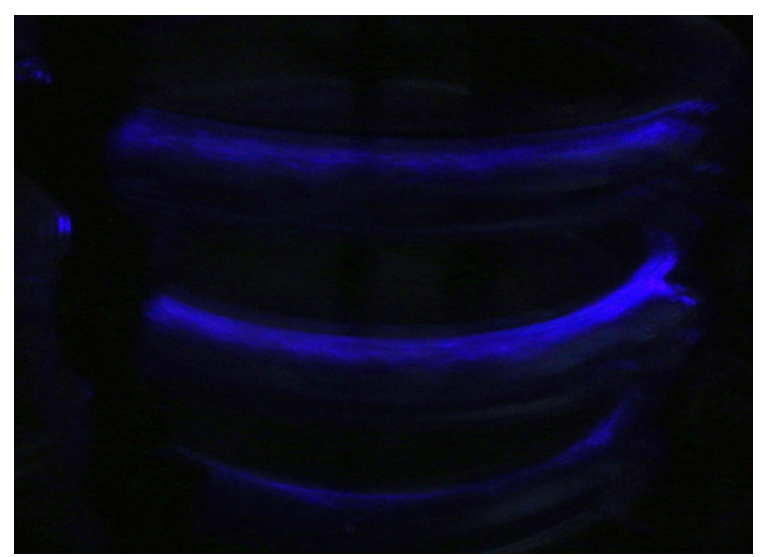

Fig.10. Glowing image of 3 layer structures in the triboplasma unit test

\section{Summary}

Shortwave emission of triboluminescence materials is investigated by means of sliding friction tester. The inorganic composide phosphors $\mathrm{Sr}_{2} \mathrm{MgSi}_{2} \mathrm{O}_{7}$ : $\mathrm{Ce}$ and organic composide phosphor Mn-PMBB are tested to have the violet-blue spectrum and green spectrum glowing respectively.

The phosphors $\mathrm{Sr}_{2} \mathrm{MgSi}_{2} \mathrm{O}_{7}: \mathrm{Ce}$ and $\mathrm{Mn}-\mathrm{PMBB}$ in forming cylindrical samples are used to constitute the vertical axis wind driving triboluminescence unit with squirrel cage structure friction pair of multi-glass bars against on the cylindrical phosphor.

The wind driving phosphor triboluminescence with persistant green glowing effect is obtained in the experiment of vertical shaft wind driving cylindrical triboluminescence unit by means of blast fan.

The triboplasmas of $\mathrm{N}_{2}$ and $\mathrm{N}_{2}-\mathrm{Ar}$ gas in the quartz tube are researched by using sliding friction of PTFE elctret on quartz tube. A high intense triboplasma light emission more than 50000 counts is obtained in the ultroviolet-purple spectrum of $310-420 \mathrm{~nm}$. This ensures an effective phototaxis trapping for pest insects.

The annular structure design of PTFE against on quartz tube friction pair with central drive shaft is sonstituted, and it is used to fabricate the S-type vertical shaft wind driving triboplasma glowing unit with three stacking layer structure of PTFE-anuular quartz tube friction pair.

The test of vertical shaft wind driving triboplasma glowing unit is conducted by means of blast fan. The violet-blue glowing band of $\mathrm{N}_{2}$-Ar gas troboplasma is obtained. It indicates the effectiveness of the triboplasma glowing unit.

\section{Acknowledgment}

$\dagger$ Work supported by grant 51375482 of the National Nature Science Foundation of China (NSFC).

\section{References}

1. B. H. Hou, C. T. Chen, L. Z. Ma and B. X. Yang. Physical agriculture-- An effective way to improve ecological environment. Environment Protection, 9(2004), 49--51.

2. B. J. Liu. Application and industrilization of Physical agriculture. Agricultural Engineering, 2,s1(2012), 4-10.

3. S. Y. Zhao and L. F. Qin. Application result of killing booworms with Jiaoduo lamp of frequency vibrication. Journal of Xinjiang Agricultural University, 25,3(2002), 71-72.

4. C. He, B. H. Fang, Y. Z. Zhang and X. G. Qing. Comparison of pest-controlling effect in rice fields between fan-inhalling lamps and frequency trembler grid lamps. Hybride Rice, 28,3(2013), 58-63.

5. Y. W. Sun. Application of physical gricultural technologies in greenhouse vegetable production. Agricultural Science \& Technology and Equipment, 8(2011), 63--64.

6. H. Guo, X. H. Han and Z. C. Xu. Effect comparison of diffrent wavelengths insecticidal lamps in lepidopteran pests trapping. Journal of Shanxi Agricultural Science, 40, 2(2012), 146-149. 